\title{
Exploration on the Ways to Develop Critical Thinking Skills in College
}

\section{English Writing Education}

\author{
Chao $\mathrm{Ye}^{1}$, Changgui He ${ }^{1}$ \\ ${ }^{1}$ Polytechnic Institute of Jiangxi Science \& Technology Normal University, Nanchang Jiangxi, China, \\ 330100 \\ 346591653@163.com
}

KEYWORDS: College Sports; Education Resources; Development and Construction

\begin{abstract}
The rapid development of computer network technology in higher education which gained wide popularity, so much for the development of distance education in the core of the concept of higher education reform began to emerge. This is mainly due to the spread of modern distance education network information due to their shared characteristics and ability to spread resources very obvious. In this context, college sports curriculum began to network resources have been developed out of the main use of the network itself to achieve two-way interactive technology, educational resources such direct and effective supplement the shortcomings and deficiencies of the traditional physical education, pole Great promoted the development of sports education. Construction of college physical education network resources are directly for the students to create a new, open learning environment to promote learning among students to establish the ideal of lifelong sports. In this paper, analysis of the development and construction of university sports network education resources, and a brief discussion for reference.
\end{abstract}

\section{Introduction}

Development of information technology to promote college sports in the modern era was a good development opportunities and challenges, most colleges and universities affected by network information, a number of new teaching techniques and tools have started to emerge. Among them, the physical education began with a variety of other disciplines education has taken a new pace of development, and therefore requires not only sports the church who have a certain expertise in sports, but also must be fully acquire the appropriate technology, so as to effectively enhance throughout the course of the overall professional level. Among some universities modernization, start the computer for the application really deep into every teacher and students work among the so-building college sports network educational resources becomes necessary, even directly affects the schools have put the school the level and quality.

\section{Development Advantages and Characteristics of the Physical Education Network New Resources}

\section{A. Students are More Scientific and Systematic Studying Sports}

Physical education information is to provide more adequate teaching content and information for students, which are based on handouts and video way to present. And when the whole function into 
full play the characteristics of the network mass information, enables effective sharing of resources, encourage students to sports and sports skills learning, get more scientific, systematic guidance. Currently, most colleges and universities within the physical education curriculum in the volume of activity in physical exercise, movement and time and frequency so there are obvious flaws and shortcomings. This must be supplemented by the construction and development of sports information network resources, prompted a wide range of sports content encyclopedia, health care and sports training techniques to achieve links to fully compensate for the amount of knowledge due to the sports teaching content and time directly caused by the insufficient. .

\section{B. To Achieve Two-Way Synchronization PE Teaching and Management}

PE curriculum content within Universities usually has its own type of teaching programs, teaching schedule requirements, to learn the content and focus, assessment, etc., which can also become a direct lesson plans or lecture notes. Many teachers can be directly through the network to learn the contents of part of lecture notes, this shared form between teachers and students to promote learning becomes more convenient. And teachers themselves can also directly some excellent curriculum, teaching record, as well as video clips uploaded directly to the internet resources which, students were able to get the first time to be able to consolidate and enhance their skills content data, the last valid achieve synchronous development of teaching management.

\section{Includes Scalability and Sustainability Characteristics}

Internet itself has significant storage features, this is one of the best stock of knowledge tools, in which students not only get to learn the current instruction, it is capable of conventional teaching and learning process directly save and share. In the past experienced physical education curriculum can be directly through the network of information resources available to the sustainability characteristics of effective access to truly achieve the longitudinal sustainability Physical Education. In addition, the contents of which have introduced and most sports are very full, real enrich students 'original sports lesson plans, and continuously expand the students' sports, physical exercise is their enthusiasm to enhance the effective play Physical characteristics of a transversely extending learning.

\section{Fusion of Campus Culture and Sports Education}

Campus culture is essential for the development of universities in terms of which the vast majority of campus culture and sports activities on campus are closely related, so the development of sports teaching resources to take full advantage of this. For example, take a picture, sound, video and animation and other media effective manner will be directly on the network schedule for health and sports activities like teaching presentation. This is the key point of the campus culture and sports teaching full integration of the respective campus held a variety of sporting events, competitions and sports, etc., can be directly through the network platform to publish directly relevant statutes and rules for competition. This is not only greatly facilitated the registration and training of people in real time, but also effectively improve the level of efficiency of their race preparation work. And sports competitions in is full of fighting spirit in which real reflects a strong campus culture, beautiful landscape becomes campus landscape culture.

\section{Building Measures of College Sports Network Information Resources}

Usually in professional sports in colleges and universities when students are learning in PE teaching courses are starting, so the corresponding sports information content of the most abundant, usually covering the students to study and work all aspects. In many ways it can be fully reflected 
this characteristic to every detail in the campus which are able to fully show the real state of the work carried out on campus. Sports Course itself as a public class courses, schools must be requested in order to carry out a more extensive physical activity, thereby increasing the effective participation of the students physical exercise among the enthusiastic demand. In the real construction of sports information resources of the process, should be set up to carry out effective web development through a wide range of lateral information must be consistent with the characteristics of the teaching institutions themselves. Construction and thereby develop Physical Education Resources Information Platform campus features properties.

Most colleges and universities already have independent of the network infrastructure and the campus site, so the development and construction work on the sports information resources have a certain foundation. In the development and construction process, it should be fully combined with the specific mission and characteristic of university party to carry out, in order to identify their specific development goals. In some professional sports among universities, construction and development information platform, still need to manage and practical assessment as the main mission objectives, and thus to the creation of the curriculum, teaching process, course selection, and query results and other extra-curricular activities improve the information platform information. And set up the platform, which can promote the students in carrying out the management aspects of the work to become more efficient and convenient. For recruit specialized sports schools train students based not only be able to fully meet their teaching network construction requirements, while expanding its functions development, give full play to the role of network applications.

Content range network teaching information resources is very broad, not just a teacher's lecture notes, but also encompasses a wide range of real-time sports news, fashion, fitness fashion, sports developments, etc. sports hot topic. These information resources must maintain timely updates and upload and requires appropriate update current popular sports topic, so as to ensure smooth flow of information resources. Alternatively, you can set up specialized sports column theoretical knowledge, students can directly achieve its theoretical significance of sport and systematic knowledge by column, in order to protect the students launched a continuation of the sustainability movement.

Construction of Sports Information Network Resource Platform, not only need more resources, work management, and real-time updates, maintenance and development of innovative and more important is the information platform. Wherein in the process of online media really created them, it is necessarily more complex, which must have the appropriate creative thinking to be maintained. Can thus since the formation of an innovative development team dedicated to develop Internet information collection, and the work of teaching resources designed to create a variety of courseware production, so as to enhance the construction of a truly effective and efficient development platform for network resources.

\section{Conclusion}

In summary, the College Sports Teaching Network Resources pre-primary is that there must be between the campus network construction and development platform, between teachers and students through the network platform, full of learning resource sharing. Through this scientific and systematic training method, students training inevitably will really develop good habits, to establish the ideal of lifelong sports. 


\section{REFERENCE:}

[1] He Wenqing. College Sports Network Teaching Platform Construction Status Analysis [J]. Education and Vocation, 2013,09: 166-167.

[2] Shi Wenyue. Status of College Sports Network Curriculum Development Division and Countermeasures [J]. Sports Science, 2013,02: 130-133.

[3] Lin Jian. The Role of College Physical Education Network Information Resources [J]. Electronic Test, 2014,11: 82-83.

[4] Liu Hong. The Development and Construction College of Physical Education Network Information Resources [J]. Modern Sports Science, 2014,13: 82-83.

[5] Liu Huaijin, Zheng Weitao. Modern Physical Distance Education Network Resources Construction and Practice [J]. Sport Science \& Technology, 2011,06: 30-32. 